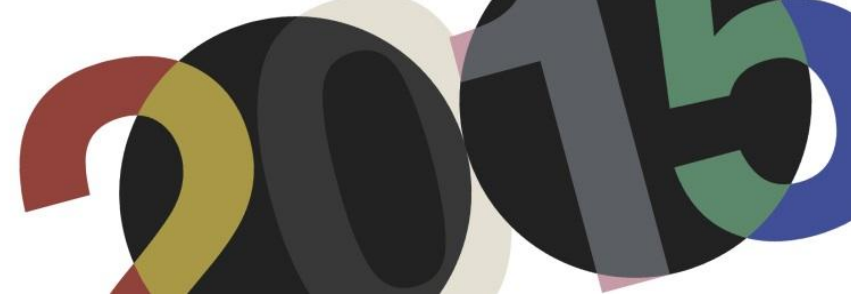

DOI: http://dx.doi.org/10.4995/LC2015.2015.931

\title{
Rem Koolhaas: Le Corbusier through the Looking-Glass
}

\author{
B. Villanueva Cajide
}

Prince Sultan University Riyadh, Saudi Arabia. Escuela Superior de Arquitectura de Madrid, España

\begin{abstract}
The present work aims to recover the part of Le Corbusier's theoretical production that can be defined as Manifesto to analyze it since its comparison with the analogue written by Rem Koolhaas. Due to the brevity of the present paper it will be focus on the analogies between two main Manifestoes: Towards an Architecture (Le Corbusier, 1923) and Delirious New York (Rem Koolhaas, 1978). The dialectic between these two Manifestoes is summarized in four main points: the intention of the text-rasion d'être-, its structure, the tone they used for the correspondent Manifesto and the relationship with the architectonic work of the authors. As we will see, theoretical and audiovisual strategies are duplicated from the master to the pupil who, on top of that, is able to reinterpret and manipulate them in a way that makes possible for his Manifesto to be considered even more efficient than Le Corbusier's, at least, in its intention to involve the largest number of people. This is possible thanks to the knowledge that Koolhaas has over media, cinema and latests technologies that allows him to express what could be identified with Le Corbusier's original ideas but in a contemporary way, so they seem to be brand new and much more understandable for today's society. In this way, Koolhaas could be understood also as a kind of Le Corbusier living in the world Through the Looking-Glass organized as Lewis Carroll did in his famous book Alice's Adventures in Wonderland. Through the Looking-Glass and What Alice Found There.
\end{abstract}

Keywords: Manifesto; Le Corbusier; Koolhaas; theory; architecture; communication.

\section{Introduction}

In 1923 Le Corbusier wrote Vers une architecture, a collection of essays which, acting as small pieces of a big Manifesto, were trying to establish a theoretical foundation for the architectural revolution that the author felt as pioneer and responsible for. The selection of the text, the images and, over all, the chosen tone are not but confirming Le Corbusier's intention to communicate his newest ideas to a large segment of society, akin to what the artists of the Avant-Garde were doing since the beginning of the 20th century using the Manifesto because of its educational capacity and theoretical immediacy. As they were intended to change the word of art completely, they decided to adapt to this end the same format that it has been primarily used by the more revolutionary political movements in History, since the Declarations of Independence of the new European countries in the 16th century to the paradigmatic Manifesto wrote by Marx and Engels that settled the basis of the the new Communist world that became real in the Soviet Union. All of them were looking for the citizen's commitment with the new cause they proposed and, because of that, the language they used was direct, clear and understandable for the whole society so they were able to join the particular revolution. It is precisely the search for this complicity the main goal for the theoretical production of Rem Koolhaas, possibly one the most influential architects of the contemporary architectonic scene who, taking advantage of his previous background as journalist, has developed a rich theoretical production following the steps of Le Corbusier in form and substance.

The present work aims to establish an analogy between Towards an architecture (Le Corbusier, 1923) and Delirious New York (Rem Koolhaas, 1978) understood as Manifestoes that can define the main concerns of the architects and authors at the time they were written. To describe the evolution between these texts four points will be analyzed: fist of all, the reason why their authors, in such different periods decided to use the form of a 
Manifesto; secondly which kind of structure they used and if it can be understood as belonging to the same kind of text; thirdly, how the tone of the Manifesto is changing along the years and why, as well as how this change is affecting the way they can communicate and the last point to be analyzed would be the relationship between theory and practice or how the Manifesto is translated, if so, to the architectonic design. The goal of the process will be to understand how the form of the Manifesto is used in both architects and, eventually, which kind of connections could be established between Le Corbusier, representing the Modernity, and Rem Koolhaas, as contemporary architect. Social, political, economical, philosophical and other aspects that can affect to the evolution in the architectonic ideas or design will be explained as part of those four main points, in order to understand them as a whole as well as for being the present paper focused on the roll of the architectonic Manifestoes.

Although the architectural work is shown as a product of a previous reflection that, in both cases, is also linked to the architects'social commitment, as solution for a given problem to get an important improvement for architecture regarding substantial social issues, the present research is willing to demonstrate how the process is actually the other way round: from an initial purely design idea all the texts are prepared to establish the appropriated theoretical frame for this first idea. In other words, we can say that theory (Manifesto), is used as a marketing tool to make more attractive the final architectonic product creating, eventually, a need in the population that did not exist before. As we will see this tendency does nothing but increase over the years and has served on many occasions to justify the expensive iconic architecture.

The conclusion of this line of thought is evident in the contemporary architecture: the building becomes an object, an icon, a Manifesto in itself. As we will see, this process was started, as many others, by who is considered the master between masters of Modernity: Le Corbusier. Going back to review their Manifestoes maybe we have the chance to come back also to the times when they were much more than marketing tools.

\section{Characteristics of the Manifestoes}

After its birth as a political tool the Manifesto is first use in art during the Avant-Garde era. Regarding the architectonic Manifestoes in architecture this period is not really important, as the lack of freedom of the discipline did not allow architects to "break the boundaries" as much as other Avant-Garde artist could do. However, there are some Manifestoes that deserve a special consideration, such as Futurist Architecture ${ }^{1}$, Manifesto $I^{2}$, Realistic Manifesto ${ }^{3}$ or Suprematist Manifesto ${ }^{4}$ to name some of the most important.

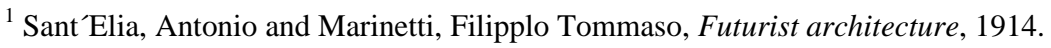

${ }^{2}$ D’Stjl, Manifesto I, 1918. Later this Dutch group will write other Manifestoes such as: Creative Demands in 1922 and Manifesto $V$ in 1923 among others.

${ }^{3}$ Gabo, Naum and Pevsner, Antoine, Realistic Manifesto, 1920.

${ }^{4}$ Malévich, Kazimir, Suprematist Manifesto, 1924.
} 


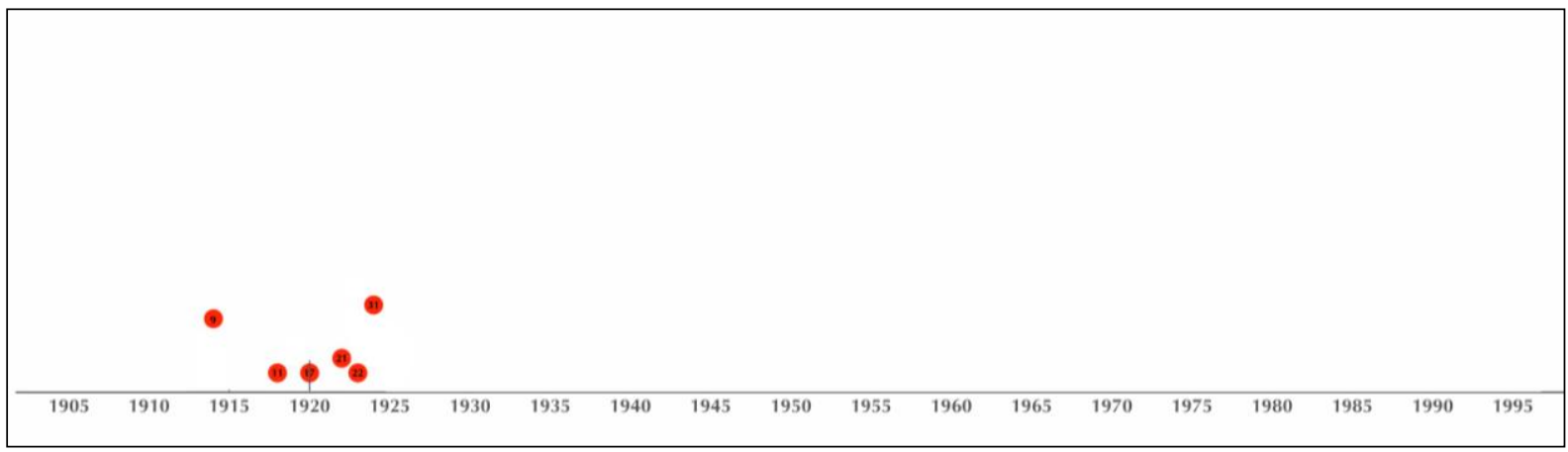

1. Chronological distribution of the Manifestoes written inside one of the Avant-Garde movements belonging to the discipline of Architecture.

Before those Manifestoes there were some others focused on architectonic concerns exclusively, that can be understood inside a context of the search for what was called the "new architectonic language", clearly influenced by the Industrial Revolution. The dialectic between the architect understood as an artist and the architect aligned with the new profession of engineer is clear in Thesis and Antithesis of the Werkbund ${ }^{5}$, a Manifesto from 1914 consistent in two antagonistic decalogues written by Herman Muthesius and Henry van de Velde.

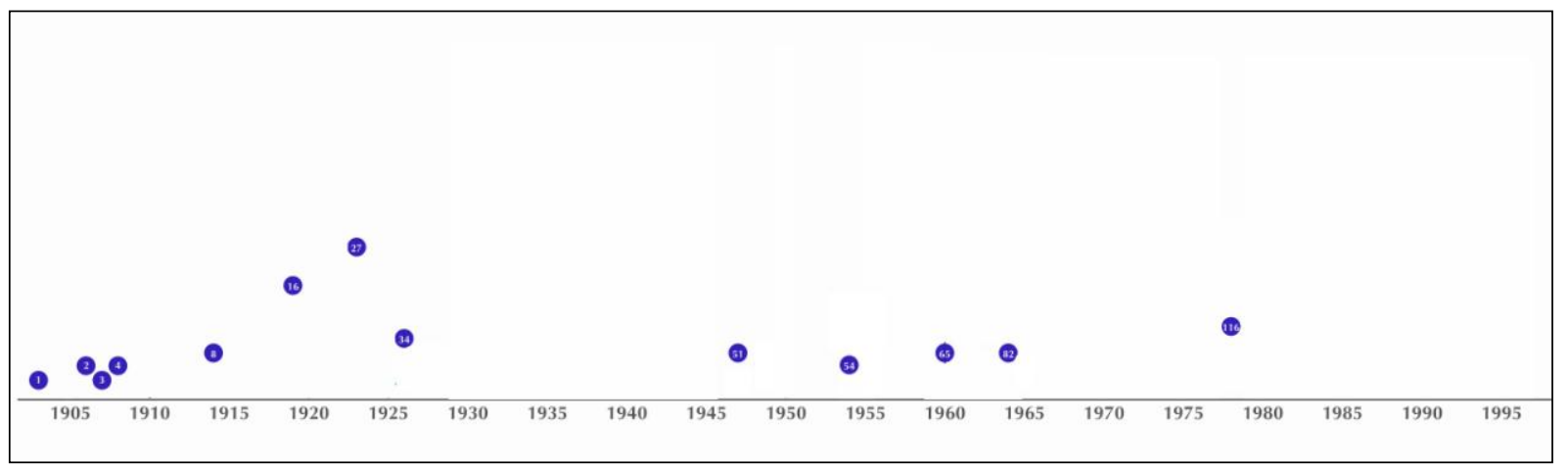

2. Manifestoes that are, in a way or another dealing with the relationship between art and industry, that started as a consequence of the changes introduced by the Industrial Revolution.

The 1920s are the years of the first peak in the production of the architectonic Manifesto when the previous issues, as well as the influence of the communist ideas coming from the Soviet Union through its Avant-Garde movements, started to create what is now understood as the Theoretical frame of the Modernity. Most of the socalled masters of the Modern Movement will write their own Manifestoes in those years. That is the case of Le Corbusier and the essays that will be collected in Towards an Architecture in 1923. Other examples are Organic architecture $^{6}$ or Working Thesis. ${ }^{7}$

\footnotetext{
${ }^{5}$ Muthesius, Hermann and van de Velde, Henry, Thesis and Antithesis of the Werkbund, written for the first exhibition and Conference of the Werbund, held in Cologne in 1914.

${ }^{6}$ Wright, Frank Lloyd, Organic Architecture, 1910.

${ }^{7}$ Mies van der Rohe, Ludwig, Working thesis, 1923.
} 


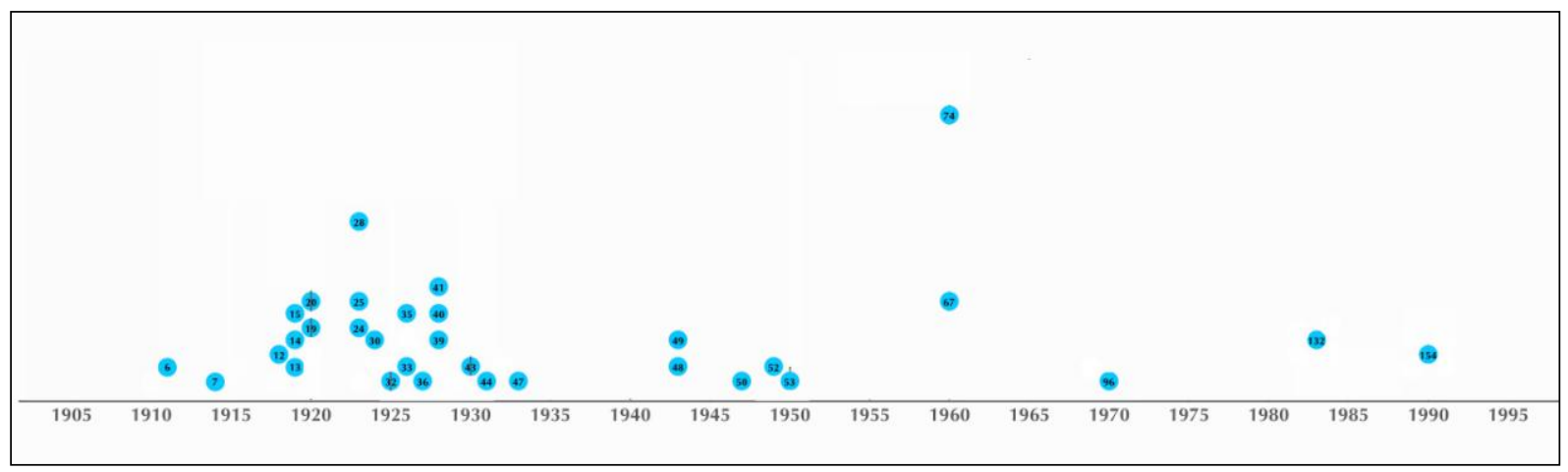

3. Group of Manifestoes that constitute the theoretical frame of the Modernity. Although they are mostly in the between wars period there are some echoes until the end of the past century

The unquestionability of the principles of the Modernity and the urban planning proposed in the Charte $d^{\prime}$ Athènes ${ }^{8}$ lasted until the Doorn Manifesto ${ }^{9}$, formulated by the new generations of the CIAM, THE TEAM 10, who were looking for more human cities: again looking for a new and better world.

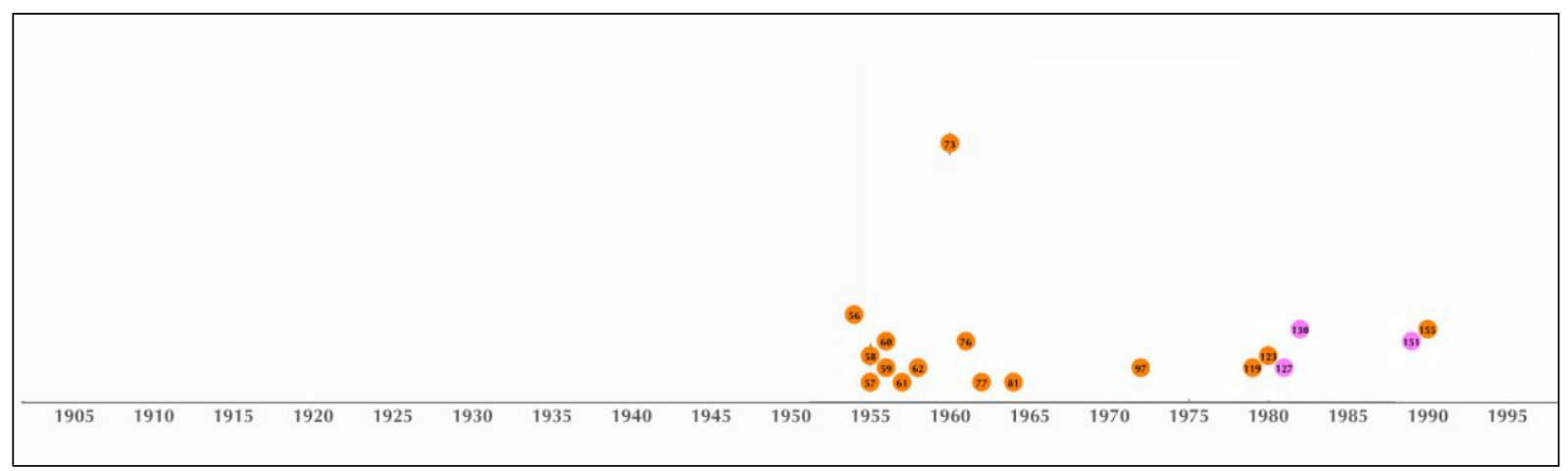

4. The review of the Modernity is a long outstanding issue that started around 1950s, as it could be seen in the graphic above and is still ongoing.

Until this era, the Manifesto was attached directly to the concept of Utopia, but around the 1950s, with the declaration of the death of the big Utopias, and after a last breath in the 1960s with the Manifestoes dedicated to imaging a new and perfect world based on the latest technologies, such as: The architect as world planner ${ }^{10}$, The ten principles of space town planning ${ }^{11}$, Universal Structure ${ }^{12}$ or No-plan ${ }^{13}$, a new era started to the architectonic Manifesto far from Utopian concepts. It will be also decisive the idea of "gentle Manifesto" formulated in the famous Complexity and Contradiction in Architecture by Robert Venturi.

\footnotetext{
8 CIAM IV, 1933.

${ }^{9}$ TEAM 10, Doorn Manifesto, 1968.

${ }^{10}$ Buckminster Fuller, Richard, The architect as world planner, 1961.

${ }^{11}$ Friedman, Yona, The ten principles of space town planning, 1962.

${ }^{12}$ Archigram, Universal structure, 1964.

${ }^{13}$ Price, Cedric, No-plan, 1969.
} 


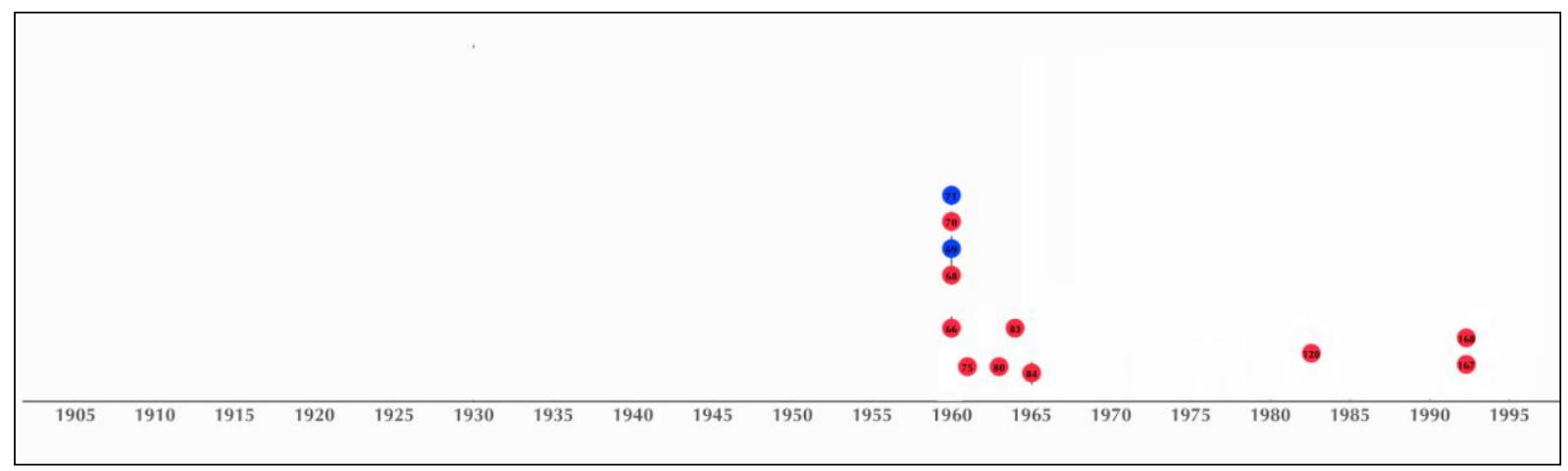

5. Last peak of the Utopian Manifestoes was during the 1960s with the Technological utopias, which are now coming back in the present century due to the review of those Manifestoes.

The contemporary Manifesto, disconnected from the concept of Utopia and using a tone not longer identifiable with the radical and angry one used by the first Manifestoes in Architecture, starts a complete transformation towards a new format. In this moment is when Rem Koolhaas wrote his "retroactive Manifesto for Manhattan": Delirious New York ${ }^{14}$, starting with a question in the introduction that shows his clear intention of using the specific format of the Manifesto for his book:

"How to write a manifesto - on a form of urbanism for what remains of the 20th century - in an age disgusted with them? The fatal weakness of manifestos is their inherent lack of evidence. Manhattan's problem is the opposite: it is a mountain range of evidence without manifesto. "Rem Koolhaas ${ }^{15}$

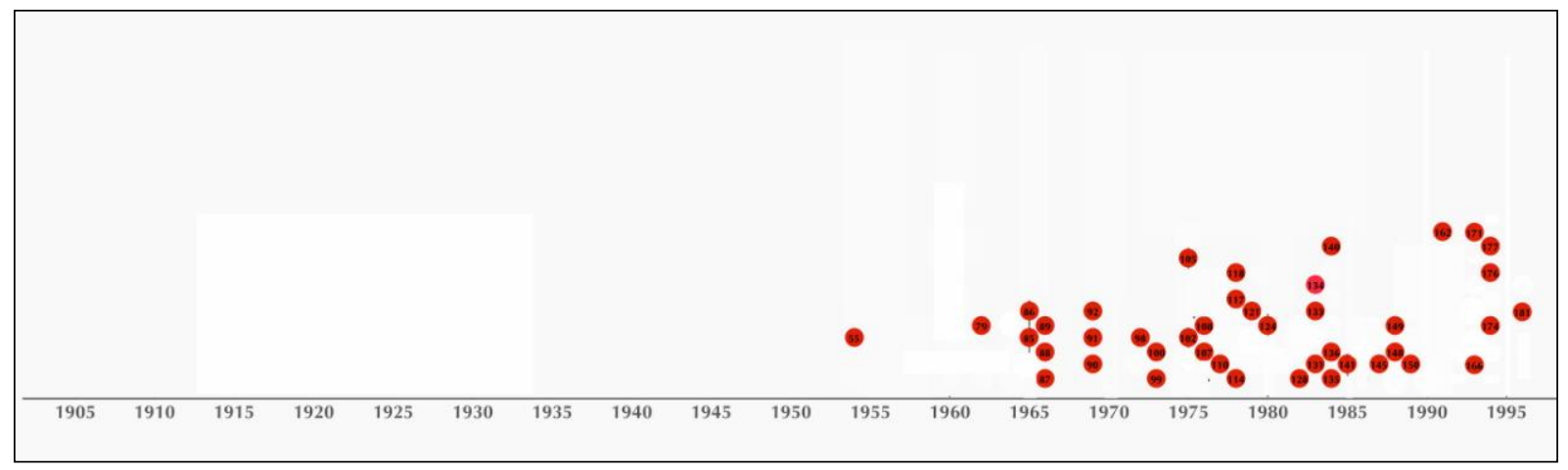

6. After the death of the Utopia started a new era for the Manifesto, which is used more as a marketing tool. Post modern and contemporary Manifestoes are multiplied in the second part of the last century and the first decade of the 21 st.

\footnotetext{
${ }^{14}$ Koolhaas, Rem, Delirious New York, A Retroactive Manifesto for Manhattan, 2nd. ed. New York: The Monacelli Press, 1994

${ }^{15}$ Op.cit., p. 9
} 


\subsection{Manifesto: Raison d'être}

"How would you like to live in the looking-glass house, kitty? You can see a peep of the hallway now, since the door to our drawing room is open. It looks like our hallway. But, you know, the area we can't see might be quite different. Oh, kitty! Let's pretend there's a way in. Let's pretend the glass is soft, so we can get through. Why, it's turning into a sort of mist now! It'll be easy enough to get through. "Alice ${ }^{16}$

However, Rem Koolhaas decided to use the format of the Manifesto despite its proliferation and the impossibility of being probed. The second problem is not important for him as Manhattan is already finished, but to consolidate his text as a Manifesto seems to be the only way he can use to theoretically dignify the island of Manhattan.

As it is established in the previous section, the situation in the year 1923, when Le Corbusier wrote Vers une architecture, is completely different. The Manifesto was the natural format to express new ideas as it had been settled before during the identity crisis architecture suffered after the Industrial Revolution and, mainly, with the birth of Engineering.

What remains clear comparing both Manifestoes is that, more than 50 years after, there is not other format as clear as the Manifesto to explain new ideas. The direct and radical language, even the simple word "Manifesto" seems to be the best way to indicate the intention of breaking with the status quo, to start from scratch.

When Le Corbusier wrote the essays collected in Towards an architecture his intention was to explain to the public what the changes he believed were necessary to get to this new order were exactly: the Modern Architecture. As it was said, in 1923 the Manifesto was the usual form to do that. So, in a way, he was doing nothing but following the normal way of communicating this kind of messages to the public.

On the contrary, the election of Koolhaas regarding the form of a Manifesto does not seem to be so logical, as himself has settled in the previous quote. However the author is sure that for Manhattan is mandatory to have a Manifesto, it needs it to make sense and, at the same time, to acquire the importance this part of the city of New York should have in the History of Architecture.

So, while in Le Corbusier's Manifesto we can perceive an evident dogmatic intention of explaining the changes to the uniformed society, in Koolhaas' the need of communicate is the same -or even more- but the intention is different. Koolhaas is using the Manifesto not to explain Manhattan but to dignify it. The difference between the raison d'être of the two Manifestoes is equivalent to the difference we can find between the Propaganda and the Marketing strategies: the difference between education and sale.

\subsection{Structure of a Manifesto}

"She turned her back to the house and set off down the path. She would just keep going straight until she reached the hill. Then the path gave a sudden twist and she was walking into the house again." ${ }^{\prime 7}$

This difference is crucial in the understanding of contemporary Manifestoes, the ones written from the 1970s and is visible since the organization of the Manifesto itself, in their own structures.

\footnotetext{
${ }^{16}$ Mason, Eva (retold from Lewis Carroll) Alice in Wonderland \& Through the Looking-Glass. New York: Sterling Children's books, 2009, p. 73

${ }^{17}$ Mason, Eva (retold from Lewis Carroll) Alice in Wonderland \& Through the Looking-Glass. New York: Sterling Children's books, 2009, p. 80
} 
As explained before, Towards an architecture is a collection of different essays written by Le Corbusier in Le Espirit Nouveau, the magazine that the author founded together with Ozenfant in 1920. The intention of those texts was clear and based on what was happening in other artistic disciplines since the beginning of the 20th century: to create a new architecture by destroying the formulas of the Academia. Although defending the same ideas, the ones that will be part of Le Corbusier's theoretical interests, each text was written separately, they were not conceived since the beginning to be part of a book. Actually, to collect all the texts signed by Le Corbusier was an idea of the director of the editorial La Sirène, Paul Laffite in 1922, as it is explained in the Preface of the Spanish version of the book. On the contrary, Delirious New York was conceived as a book since the beginning. The history of Manhattan, the main ideas, the explanation over the different skyscrapers and spaces of the city are situated in the right place for the message to be understood.

If Le Corbusier's statements are clear thanks to the consistency of their theoretical body, the ideas exposed in the Retroactive Manifesto for Manhattan are understood because they are consistent with the line of argument chosen by the author, like if it was a part of something that can be defined as a kind of Historiography of contemporary architecture. ${ }^{18}$

If we compare the index of the two books the difference is not that clear. Delirious New York, despite being actually written as a book, appears as an ensemble of texts dealing with different ideas, fragments of the complex reality of Manhattan itself. Each block -organized as the city blocks, like Koolhaas explained in the introductiondescribes a reality of Manhattan, and is named after each of these independent but coexistent realities: Coney Island, Skyscraper, Rockefeller Center and European. In the form of a Manifesto, the personal view of Koolhaas, mixed with some historical explanations are given to the reader to explain, not only their importance in the city, but also their importance for the city to be considered as a Manifesto itself.

The texts of the Manifesto Towards an architecture are organized by Le Corbusier according to the main idea they are dealing with. The engineer's Aesthetic and architecture, Three reminders to architects -subdivided, meaningfully, into mass, surface and plan-, Regulating lines, Eyes which do not see..., Architecture, Massproduction houses and Architecture or revolution. Written as a compilation of guide principles for the architects to design and build the new architecture, each Manifesto explains in a clear way the process they have to follow to achieve this goal or why they should do it. The consistency of the index is not showing a line of argument as Koolhaas shows in his Manifesto, but a natural order for the steps for Le Corbusier's personal recipe.

As conclusion we could say that, while Le Corbusier is using an structure in the Manifesto to explain his theories, Koolhaas is using Manhattan's structure to build his manifesto, and consequently, his theories about contemporary city and society.

\footnotetext{
${ }^{18}$ To illustrate the influence of the theories of the Historian of the Modernity, Panayotis Tournikiotis analyzed in The Historiography of Modern architecture nine essential books about Modernity written by nine historians: Sigfried Giedion and Reyner Banham together with Nikolaus Pevsner, Emil Kaufmann, Bruno Zevi, Leonardo Benevolo, Henry-Russell Hitchcock, Peter Collins, and Manfredo Tafuri.
} 


\subsection{Tone of the Manifesto}

"It's just like a chessboard!" Alice cried. She saw some men on the squares. "It's a huge game os chess!. What fun! How I wish I could play. I wouldn't mind being a pawn. Though of course I would like to be a queen best." Alice. $^{19}$

The radical attack by Le Corbusier to what he describes as "Academia" is the essence of the Manifesto Towards an architecture itself. Precisely because of the need of breaking with everything that is consider as "good Architecture" in those years he wrote the essays, founded the magazine L'Espirit Nouveau and started signing as Le Corbusier. His affirmations does not admit any question, nor his proposals. The tone of the Manifesto is showing without discussion this character: Clear, radical, dogmatic and threatening. Le Corbusier express his contempt for the grievances he has received along his life in the preface of his book:

“Maybe I am lucky of being still aggrieved at 70!' Le Corbusier ${ }^{20}$

In a more conciliatory tone, Rem Koolhaas recite all the elements that, according to him, are essential to understand the importance of the city of Manhattan in the contemporary architecture. The text was written after and under the influence of Venturi's "gentle Manifesto" on one hand, and both the idea of a Retroactive Manifesto and, on the other hand, the moral value's changes in the society between the one from the beginning of the century -the public of Le Corbusier- and the society of the end of the century. These two ideas are also connected to the death of the Utopia, sign of the times that makes necessary for the manifesto to be "retroactive".

"I thought the twenty-first century would be, hopefully, more like a dialogue, more like conversation, and maybe than itself is a kind of manifestation or whatever. I am very careful in even using that word. I just think the twentieth century was so sure of itself, and I hope that the twenty-first century will be less sure. And part of that is to listen to what other people say and to enter into a dialogue, to not stand up and immediately declare one's intent. " Tino Sehgal. ${ }^{21}$

As the Manifesto is the expression of the culture of its era, these two examples, even having the same name and similar intentions are completely different in tone as they are trying to communicate them to two completely different societies. The tone used is, in both cases the one that is more suitable for the society of the moment, taking into account its sensibility, mood and cultural background. The "between wars" society from 1923 is less sophisticated and cynical than the peaceful society from 1978. If the architects wanted their message to be assumed for the correspondent society it is mandatory for them to take these aspects into account. A mistake in the tone of the Manifesto could have the message loss as a consequence. That is the reason why these two Manifestoes are so different in tone, and consequently, the reason for their success in their respective times.

\footnotetext{
${ }^{19}$ Mason, Eva (retold from Lewis Carroll) Alice in Wonderland \& Through the Looking-Glass. New York: Sterling Children’s books, 2009 . p. 86

${ }^{20}$ Le Corbusier, Hacia una arquitectura, Barcelona: Ediciones Apóstrofe, 1998. Preface of the Spanish edition

${ }^{21}$ Sehgal, Tino, in the event Manifesto Marathon, curated by Hans Ulrich Obrist in October, 19th 2008, Serpentine Gallery, Londres.
} 


\subsection{Influences of the Manifesto in the architectonic works}

Until now, the differences between Rem Koolhaas and Le Corbusier are very clear. Both can be understood as products of their epochs that, as we have seen, were highly different. However, the points in common between the two architects are equally clear and have been developed along numerous essays and books.

As this work is focused in their capacity as Manifesto writers and, more specifically, in their two studied Manifestoes, the points in common to be described here would be also focused on this issue. Thus, one of the more important aspects to be highlighted regarding this is the relationship between the written Manifesto and the design work of Le Corbusier and Koolhaas respectively.

It is a tendency in the contemporary Manifesto to be used as a text capable of building the theoretical frame suitable for the architectonic work, specially if this work belongs to what can be described as "iconic architecture". The newness, seen as a virtue in itself is mandatory in those buildings so, as the society is not prepared to accept the iconic building easily, the Manifesto, with its direct and clear language, seems to be the ideal accomplice to achieve this acceptance.

"We might generalize by saying that form medium and small budgets the "right" supply-based demand would be to repeat what has worked in the past (...) For high budgets, on the other hand, the standard demand is for architecture to provide what is supposedly new (or exclusive, in the most repulsive and fascist sense of the word)" Eduard Sancho Pou ${ }^{22}$

Before this necessity, Le Corbusier, who was also proposing completely new ideas for the Modern Architecture, following the Avant-Garde artists as we saw before, used the Manifesto in its radical way as an instrument capable of waking up his coetaneous society and guide them to the new and better modern life.

In the same situation, 50 years after that, Rem Koolhaas will feel that the Modernity should be reviewed in a contemporary way. The city life, identified with Manhattan's, is not solved by the Modern urban planning, specially regarding what he described as the "culture of the congestion", a direct consequence of the megacities of our era.

The best example of this attempt of dealing with this "culture of congestion" is his project for the Parc de la Villete competition in 1982 in Paris. OMA's design is conceived conceptually as an American skyscraper understood a structure where a number of different activities are overlapped. By using this strategy, Koolhaas tries to solve the problem of how to combine the reality of the indetermination with the need of specificity that has the architectonic object, a problem that neither the Modernity nor its subsequent reviewers (such as the TEAM 10 for instance) could solve. This is also his first attempt of breaking the tandem form-function principle by introducing the idea of indetermination through the "activity areas", places with no specific shape. Those areas, the encounters between the users and the communication network, are the only elements in the Parc, that are conceived as a system of vectors which last definition relies on the user. The city of Manhattan understood as a system of relationships between the citizens and the skyscraper as a catalyst of the changes of the contemporary society. Both ideas, translated into concepts, will be repeated and developed along the work of the architect in the same way he did in this proposal for the park in Paris.

\footnotetext{
${ }^{22}$ Sancho Pou, Eduard, Architectural Strategies (Marketing, Icon, Politics, Masses, Developer, the N.1), Barcelona: Grup Editorial, 2012, p.9.
} 
If Rem Koolhaas will use the ideas explained in his Manifesto conceptually, as a way of understanding the contemporary society, influenced by the capitalism and translated it to a generative concept in all his projects even although there were not urban planning projects but assuming that all the buildings he design are affecting the city they belong to, as it does every skyscraper in Manhattan- the translation of the ideas explained in Towards an Architecture is more direct, so easier to understand.

As said before, Le Corbusier organized his previous Manifestoes in the book Towards an architecture in the form of a guideline for the contemporary architect being able to follow it and design modern architecture. The series of recipes mixed a change of attitude, a connection with the history of architecture -Roman architecture mostly- and proper examples on how to design. The book is clear about how Le Corbusier himself is using his statements. For example, after an explanation about the use of the regulating lines in the classic architecture, with a kind of affected shyness, he finds himself obliged to use his own buildings as examples:

"Here I excuse myself for mentioning my own examples, but, spite my researches, I did not have the pleasure of finding contemporary architects who have dealt with this question. "Le Corbusier ${ }^{23}$

To illustrate the use of this regulating lines he uses the design of the house for Ozenfant he did together with Pierre Jeanneret in 1923. The golden number is used here to make the composition of the façade, localizing every single element on it and, at the same time, to provide the small house with a sense of order, making it appear as something "monumental" between other buildings that have been build "with no rules"24 as he describes.

In both cases the design of the project itself is the ultimate goal they pursued with the Manifesto, that is just settling the basis for the new architecture to be designed -or dignified-. The main difference is the connection with this architecture. In the futuristic Manifesto Towards an architecture, Le Corbusier is facing a blank paper while Koolhaas is just writing a retroactive manifesto for Manhattan, that is already built. The connection between theory and building is inverted in the second case, so Koolhaas need to go more into conceptual concerns while Le Corbusier, paradoxically, is more realistic. Just the contrary as their Manifestoes were regarding their connection with the concept of Utopia.

\section{Conclusions. Rem Koolhass: Le Corbusier through the Looking-Glass}

"A house is a machine for living in. Baths, sun, hot-water, cold-water, warmth at will, conservation of food, hygiene, beauty in the sense of good proportion." Le Corbusier ${ }^{25}$

The second part of Alice's adventures in Wonderland, Through the Looking-Glass and What Alice Found There, describes the world on the other side of the mirror, where Alice goes in a strange way. At first, the world seems to be quite similar to the one she is living in, later it seems to be all the contrary, but at the end, when she gets to understand its structure, it seems to be more complicated: a translation to the language of the mirror of her world.

More than often, the work of Le Corbusier and in general, of all the Modern architects, is understood as a translation of the classical architecture language to a new -modern- one. This affirmation is clear in the structure

\footnotetext{
${ }^{23}$ Le Corbusier, Towards an Architecture, New York: Holt, Rinehart and Winston, 1986, p. 62.

${ }^{24}$ Le Corbusier, Towards an Architecture, New York: Holt, Rinehart and Winston, 1986, p. 62.

${ }^{25}$ Le Corbusier, Towards an Architecture, New York: Holt, Rinehart and Winston, 1986, p. 89.
} 
of Le Corbusier Manifesto Towards an architecture. Despite being a collection of essays, written in different moments, the consistency of the ideas of the architect are extremely clear the same as is path that needs to be followed to get to this new order he describes and which constitutes the Modern Architecture. Path that starts with the classic architecture, saw as an stated point to learn from. In this sense, the translation of the classic architecture is evident, and so it is the rejection of the literal translation (imitation) proposed before by the Academy. As he explains in the Ozenfant's house façades, although the regulating lines are used like the Roman or Greek did before, the introduction of new modern elements, such as large ribbon windows and the geometrical abstraction, leads the house to what he describes as a new order. This process is the exact definition of translation and it could be the main reason for the success of the Modernity in the first place.

In the case of Koolhaas the translation is not that immediate, moreover, it is consciously complex. The use of Manhattan as a main example, as a generator of the change in the conception of the contemporary architecture is also an attempt to avoid any connection with history, using a city that he considers that has been started from scratch as a product of the desire of the capitalist contemporary society. He sees an example of that in Coney Island or the Rockefeller Center. The elements of the city are not explained here since their design, which remains as something unimportant, but since their capacity of canalizing the "congestion", main definition of the contemporary culture. Manhattan is a city made to satisfy our desires, what it is more interesting than its urban planning. Desires, on the other hand, that did not exist before, as they are directly connected to the contemporary way of living and understanding economics, politics or social relationships. But, although it locates Koolhaas in the antipodean from Le Corbusier the truth is that they are closer than it seems. In fact, Le Corbusier is for Koolhaas exactly the same as the classicism was for the master of the Modernity: the starting point from where to start the translation.

"Le Corbusier devouring ambition is invent and build a "new city" in accordance with the demand and potential splendour of the machine civilization.

His tragic bad luck is that this city already exist when he is developing his ambition: is, concretely, Manhattan"Rem Koolhaas ${ }^{26}$

So, despite the apparent differences between the two architects, forced by Koolhaas himself, they found a common point precisely in Manhattan, exemplary city for Koolhaas and, according also to him, the city Le Corbusier was, once and again, trying to create, without success. Thus Koolhaas is, at one time, the one responsible for the approach and distance of his own ideas from Le Corbusier's.

The lack of references to Le Corbusier, who is constantly present in Koolhaas work, could be nothing more but an attempt for the pupil to be released from the master. Like the characters in Lewis Carroll's books, Koolhaas is, absolutely aware of living in the world through the Looking-Glass. This fact is not making him, however, stop running away from this reality.

"-Well, this is what happens when you life upside down-said the Queen; and added complacently-: I have to admit that, at first, one get a little bit sick "Lewis Carroll ${ }^{27}$

\footnotetext{
${ }^{26}$ Koolhaas, Rem, Delirious New York, A Retroactive Manifesto for Manhattan, 2nd. ed. New York: The Monacelli Press, 1994, p. 249.

${ }^{27}$ Carroll, Lewis, Alicia en el País de las Maravillas, Madrid: Anaya, 2009, p. 202.
} 
The logical explanation could be that, the same as in Carroll's book, it could be possible that our reality is also taking place on top of a big chessboard from whose rules there is no escape.

Once Alicia got into the world inside the mirror she discovered that it was completely different form the one outside. She could not understand the rules, she was completely lost. But actually, as we see at the end of the book, she was the one who was creating this world, those rules and even the sensation of being lost, because all of this was part of her dream, her imagination. In other words, we can say that Alicia was doing nothing but transforming the world she knew into another invented one that was the result of the translation of her surrounding reality into another one built thanks to two main operations: symmetry and contrary. This strategy is broken with the introduction of the chessboard, representing an structure that is exactly the same in both sides of the mirror. Even the rules are the same. So she can only explain the world through the looking-glass by locate it in an intermediate state between being symmetrical and contrary to the world from Alice's side of the mirror.

The need for an old structure, something we can understand and, therefore break, is a common point of start at the beginning of a new era, specially in Arts and Architecture. The translation from the Classicism was the more criticised aspect of the "Revolution" Le Corbusier started with the Modernity. He was looking for a new language able to represent the new values of the Modern society, claiming against the Academia but using the same basis, how is it possible? his detractors said. Now we found out that Rem Koolhaas, like Alice, is creating a new world from Le Corbusier's Modern one like if it was looked through a looking-glass. The way he uses the small scale -Conney Island- to explain the big one -Manhattan-, the translation of the values of the new society from the social ones settled by Le Corbusier to the contemporary capitalism based ones, and even the structure of his manifesto explained in the index are just the translation of Le Corbusier theoretical strategies. Rem Koolhaas is playing in Le Corbusier's chessboard following his rules. If Le Corbusier was translating the Classic principles in Architecture to the Modern ones, Rem Koolhass, by translating Le Corbusier's, is retaking the Classicism, putting them into contemporary words but without changing their structure. By doing this, there is no other option that considering that, far from disappearing, the Modernity is being constantly reviewed and we can consider, in this way, that Rem Koolhaas is, in Charles Jencks words ${ }^{28}$, a Late Modern, which could led us to the conclusion than the Neo-Modernity and even the Post-Modernity are just punctual tendencies inside the process of building the Modern Movement, still ongoing.

\section{Source of images}

All images or tables accompanying this paper have been produced by the author herself. The Manifestoes included in the tables were found in the books Programs and Manifestoes on 20th century architecture, (Conrads, Ulrich Cambridge, Massachusetts: MIT Press, 1970) and Theories and Manifestoes of contemporary architecture, (Jencks, Charles and Kropf, Karl, Chichester: Academy, 1997)

\section{Acknowledgement}

The author acknowledge the support of Prince Sultan University in Riyadh, Saudi Arabia, during the research which has made it possible this paper and previous analysis.

\section{Bibliography/references}

\footnotetext{
${ }^{28}$ Jencks, Charles, The New Moderns. From Late to Neo-Modernism, Academy, Chichester, 1997.
} 
Carroll, Lewis, Alicia en el País de las Maravillas, Madrid: Anaya, 2009.

Conrads, Ulrich. Programs and Manifestoes on 20th century architecture, Cambridge, Massachusetts: MIT Press, 1970.

Jencks, Charles, The New Moderns. From Late to Neo-Modernism, Academy, Chichester, 1990.

Jencks, Charles and Kropf, Karl, Theories and Manifestoes of contemporary architecture, Chichester: Academy, 1997.

Koolhaas, Rem, Delirio de Nueva York, Barcelona: Editorial Gustavo Gili, 2007.

Koolhaas, Rem, Delirious New York: a retroactive manifesto for Manhattan, London: Thames and Hudson, 1978.

Le Corbusier, Hacia una arquitectura, Barcelona: Ediciones Apóstrofe, 1998.

Le Corbusier, Towards an Architecture, New York: Holt, Rinehart and Winston, 1986.

Mason, Eva (retold from Lewis Carroll) Alice in Wonderland \& Through the Looking-Glass. New York: Sterling Children's books, 2009.

Moneo, Rafael, Inquietud teórica y estrategia proyectual en la obra de ocho arquitectos contemporáneos, Barcelona, Editorial Actar, 2004.

Tournikiotis, Panayotis, The Historiography of Modern Architecture, Cambridge, Massachusetts: MIT Press, 1999.

Venturi, Robert, Complexity and Contradiction in Architecture, New York: Museum of Modern Art Press, 1966. 